\title{
INTEGRATING SAP PROJECT SYSTEM INTO AN IS PROJECT MANAGEMENT COURSE
}

\author{
Ming Wang, California State University, ming.wang@calstatela.edu \\ Lei Jin, San Francisco State University, jinlei@sfsu.edu
}

\begin{abstract}
The project management course is one of the most important IS core courses in the Information Systems (IS) curriculum. Although Microsoft Project is widely adopted in IS project management courses for project planning and scheduling, it is relatively difficult to track the actual project cost and to manage the complete project life cycle because it is not integrated into ERP systems. Recognizing the limitations of Microsoft Project as a project management tool, the authors proposed a comprehensive framework to incorporate ERP Project Systems into the project management curriculum in addition to Microsoft Project. This paper provides the course design, course materials, delivery method, and student learning outcomes assessment. The data analysis of the course assessment indicates significant improvements on student learning outcomes and positive learning experiences. The purpose of the paper is to provide a guideline for those who seek to incorporate ERP technology in the IS project management curriculum.
\end{abstract}

Keywords: IS Project Management, SAP Project Systems, IS curriculum, Project Management, SAP ERP

\section{INTRODUCTION}

Organizations increasingly invest in information technology (IT) to gain operational efficiency and competitive advantage. In the US, companies spend more than $\$ 250$ billion each year on IT projects. On average, IT investment accounts for about 40 percent of a company's annual capital expenditure. Despite the large investment, the majority of IT projects failed to achieve development goals on time and within budget (CHAOS Report, 1995). Effective management of IT projects is a serious organizational challenge. IT project management knowledge and skills have been identified as one of the most important competencies for today's IT professionals.

As illustrated by the recent research within the IS Education field, IS Project Management is ranked as the third most popular among the seven IS core courses in 2010 (Huang, Ma \& Wang, 2014). The survey indicates the course is offered in 261 out of 394 (66.2\%) IS programs in the United States, slightly below widely covered Data and Information Management and System Analysis and Design courses. In addition, an IS Project Management course is core in both IS 2010 Curriculum Guidelines (Topi, et al., 2010) and the proposed IS 2015 Curriculum Guidelines (Rosenthal and Dhariwal, 2015). Both Guidelines recommend that the IS Project Management course should address the following perspectives:

"This course discusses the processes, methods, techniques and tools that organizations use to manage their information systems projects. The course covers a systematic methodology for initiating, planning, executing, controlling, and closing projects. This course assumes that project management in the modern organization is a complex team-based activity, where various types of technologies (including project management software as well as software to support group collaboration) are an inherent part of the project management process. This core course is primarily focused on initiating, planning, executing, controlling, and closing information systems projects. Implementation of ERP project management software in the course will provide students hands-on experience on all the project development phases."

Project Management Body of Knowledges (PMBOK, 2008) published by Project Management Institute (www.pmi.org), is an important document that defines the sum of knowledge as well as the common lexicon within 


\section{Issues in Information Systems \\ Volume 17, Issue IV, pp. 42-50, 2016}

the profession of project management. It is also widely adopted as the framework to guide the content of textbooks in this area. According to the PMBOK, the nine knowledge areas of project management include:

1. Project integration management: integration management focuses on coordinating the project plan's development, execution, and change control. Its processes are primarily integrated with activities/processes of other knowledge areas.

2. Project Scope Management: scope management ensures that the project's work is specified accurately and completely. It primarily involves defining and controlling what is or what is not included in the project. In addition, proper scope change procedures could be implemented to reduce scope creep.

3. Project Time Management: Time management involves developing, monitoring, and managing the project's schedule to ensure timely completion of the project.

4. Project Cost Management: Cost management includes processes to plan, estimate, budget and control cost to ensure that the project is completed within the approved budget.

5. Project Quality Management: Quality management includes processes such as quality planning, quality assurance, and quality control to ensure that the project will satisfy or exceed stakeholder needs and expectations.

6. Project Human Resource Management: Human resource management includes the processes that organize, manage, and lead the project team. It ensures the most effective use of the people involved with the project.

7. Project Communication Management: Communication management includes the processes required to ensure timely and appropriate generation, collection, dissemination, storage, and ultimate disposition of project information.

8. Project Risk Management: Risk management includes the processes concerned with identifying, analyzing, controlling, and responding to project risk.

9. Project Procurement Management: Procurement management ensures that the required products and services from outside the organization are acquired/purchased properly.

Even though many software tools have been developed to assist project managers, given the complexity and interactive nature of project management processes, it is challenging to create tools that provide integrated support of the complete nine knowledges areas of project management across its entire lifecycle.

As an important software tool specializing in project management, Microsoft Project is widely taught in an IS project management related curriculum. The software is easy to use and sufficient for project planning and scheduling purposes, but it is difficult to implement the entire project management lifecycle as specified in the above course description defined in IS 2015 Curriculum Guideline (Rosenthal and Dhariwal, 2015). For example, Microsoft Project is stand-alone, single-user software, and it is difficult to share and update in a team setting. Because it is not integrated in any ERP systems, it is not sufficient to calculate the actual project cost in real time due to missing financial accounting, managerial accounting and human resources data in the enterprise system (Franz, 2015). Even though including Microsoft Project in IS curriculum is convenient and necessary, it cannot replace the power of ERP project management tools. In addition, it is possible to integrate Microsoft Project with the SAP ERP system (Microsoft Project Server, 2012). 


\section{Issues in Information Systems \\ Volume 17, Issue IV, pp. 42-50, 2016}

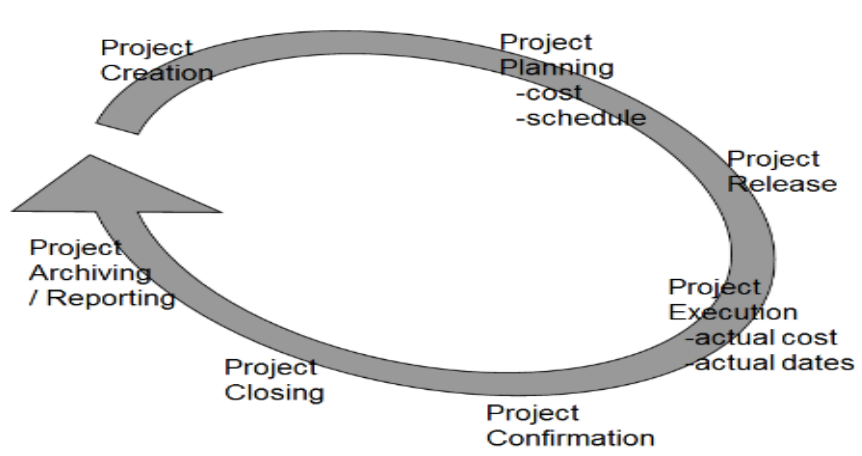

Figure 1. Project Management Cycle

The proposed course examines the unique characteristics of IT projects and introduces the students to a variety of project management techniques that can be applied in an IT project management context. More specifically, this paper provides a new framework of integrating the ERP project system in an IS Project Management course using SAP University Alliances Project System curriculum materials (Wassmann and Wilder, 2012). Figure 1 shows the full project management cycle in SAP ERP. This proposed approach will provide students with in-depth IS project management knowledge and extensive skills which they will need for their project management career development. This paper is intended to serve as a useful teaching resource for IS educators who seek to teach ERP systems in a college of business. The remainder of the paper will specify how to integrate SAP ERP to the IS project management course in the proposed framework in the following four sections: ERP Project management systems, proposed ERP project management framework, assessment of learning outcomes and conclusion.

\section{ERP PROJECT MANAGEMENT SYSTEM}

SAP ERP systems are generic, packaged software systems that provide comprehensive functionality and business processes integration across the enterprise e-business platform with its centralized data repository shared by all the business processes. Unlike other project management software, the SAP ERP Project System has the multidisciplinary scope of enterprise system that requires internal cross-disciplinary coordination (Anderson, et al., 2009). According to Franz (2015), SAP ERP Project System is one of the few project management tools that are able to completely map the entire life cycle of a project, and closely integrate with accounting, materials management, sales, production, human resources, and finance accounting and controlling modules of SAP ERP system.

Those project managers who rely on project management tools without such integration features often have to enter project data, such as cost information or time data several times, resulting in inefficiency and project failure. SAP PS is able to effectively carry out project planning, execution, and control processes, improving the chance of project success by appropriately managing scope, time and cost of an enterprise project. Figure 2 illustrates how the SAP ERP Project System is integrated to Financial Accounting (FI), Controlling (CO), Project System (PS), Sales \& Distribution (SD), Material Management (MM), Production Planning (PP), \& Plant Maintenance (PM), Human Resources (HR). 


\section{Issues in Information Systems \\ Volume 17, Issue IV, pp. 42-50, 2016}

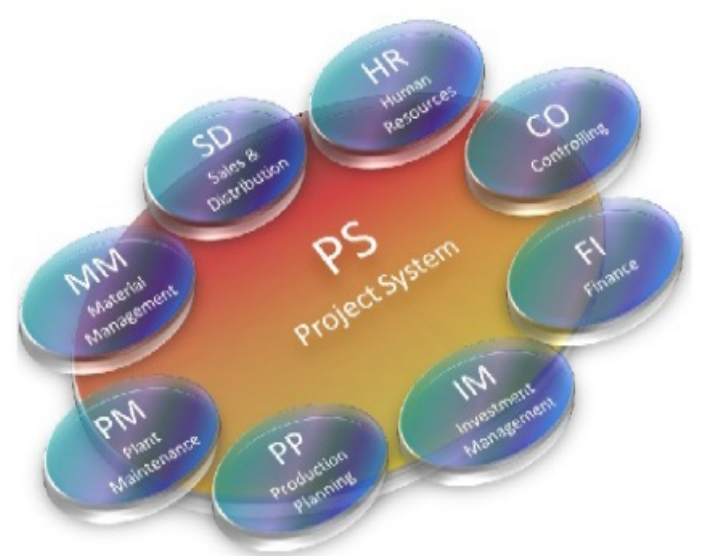

Figure 2. PS and SAP Application Modules

\section{PROPOSED COURSE FRAMEWORK}

The proposed IS Project Management Course introduces students to fundamental project management principles, theories, and best practices as described in the Project Management Institute's PMBOK Guide. "Information Technology Project Management" (Marchewka, 2012) is used as the textbook to help students understand the unique characteristics of IT projects and major project management knowledge areas, including how to effectively manage project scope, time, cost, quality, and risk under IT project context. Besides project management-related concepts, this course employs hands-on exercises and tutorials to introduce effective project management tools, including Microsoft Project and SAP ERP Project Systems. In addition, this course also address the specific challenges associated with ERP software implementation, open source software adoption and outsourced IT projects through group case analysis and presentations.

SAP ERP project management knowledge and SAP ERP Project System activities are introduced in the second part of the project management course after students have hands-on experience in Microsoft Project.

At the end of the course, students will be able to:

- describe the role of PS in SAP ERP System

- explain the reasons to use SAP PS for Project Management

- describe SAP PS Structure, SAP PS Data Integration and Process Automation

- Create the Work Breakdown Structure (WBS) of a Project

- Plan cost and dates using Cost Models

- Post actual costs and dates for WBS elements

- Create reports on project plan and actual data analysis

SAP Project System course materials and the manual of hands-on activities are based on the S A P Project System curriculum developed by the SAP University Alliance, which provides free curriculum access to faculty of its member universities. The course materials have been reviewed and based on A Guide to the Project Management Body of Knowledge (PMBOK ${ }^{\circledR}$ Guide).

SAP Project System knowledge and skills are delivered with lectures, followed by hands-on experience. The laboratory manuals ((Wassmann and Wilder, 2012) focus on step-by-step instruction on task completion of seven modules of hands-on activities. The combination of hands-on laboratory learning and project management process concepts learning via reading, discussion, and the business case study is a powerful and effective approach to learn SAP ERP Project System. It is a challenge to balance the two streams and relate the hands-on learning with project management major body knowledge areas in the course. But these learning by doing activities really help students to integrate theory with practices of effective project management. 


\section{Issues in Information Systems \\ Volume 17, Issue IV, pp. 42-50, 2016}

\section{ASSESSMENT OF LEARNING OUTCOMES}

In order to verify the effectiveness of the developed framework, authors developed a SAP Project System (PS) Survey instrument based on SAP (PS) learning objectives for one metropolitan public universities. The survey includes assessment of student SAP Project System knowledge, skills and learning experiences. The pre-survey and post-survey were conducted in the two sections of IT Project Management classes in the spring semester and one section of the same class in the fall semester of 2015. During the spring semester of 2015, among the 66 enrolled students, $45(68 \%)$ of them are undergraduate students major in Information Systems from the College of Business, and $21(32 \%)$ of them are graduate students major in Computer Science and Software Engineering from the College of Engineering. During the fall semester, $32(82 \%)$ out of 39 enrolled students are undergraduates from College of Business, and the other $7(18 \%)$ are graduate students from the College of Engineering. The questionnaire survey measures students perceived SAP ERP PS knowledge, skills and learning experiences using the Likert Scale from 1 to 5 .

In spring 2015, sixty-five out of 66 students who took the IS project management course participated in the presurvey. Fifty-one students participated in the post-survey. In fall 2015, 37 out of the 39 enrolled students took the pre-survey, and 39 out of 39 enrolled students took the post survey. The rating scale is from lowest to highest. The post survey includes students learning experience category in addition to knowledge and skills. Descriptive analysis was performed on the collected data for both semesters.

Figure 3 compares the pre-survey and post-survey results regarding students' perceived SAP PS knowledge in spring 2015 and fall 2015. As illustrated in Figure 3, student ratings in the seven areas of SAP PS are increased by at least one point in the post survey. However, the overall post-survey ratings of the seven survey items are between 3 and 3.5, this indicates that using SAP PS to manage projects effectively requires a comprehensive understanding of ERP business processes integration. The learning experience could be overwhelming for students who take an IS Project Management class without taking the ERP business process class first. Therefore, there is room to improve the ratings in the future.

\section{SAP Project System Knowledge Rating}

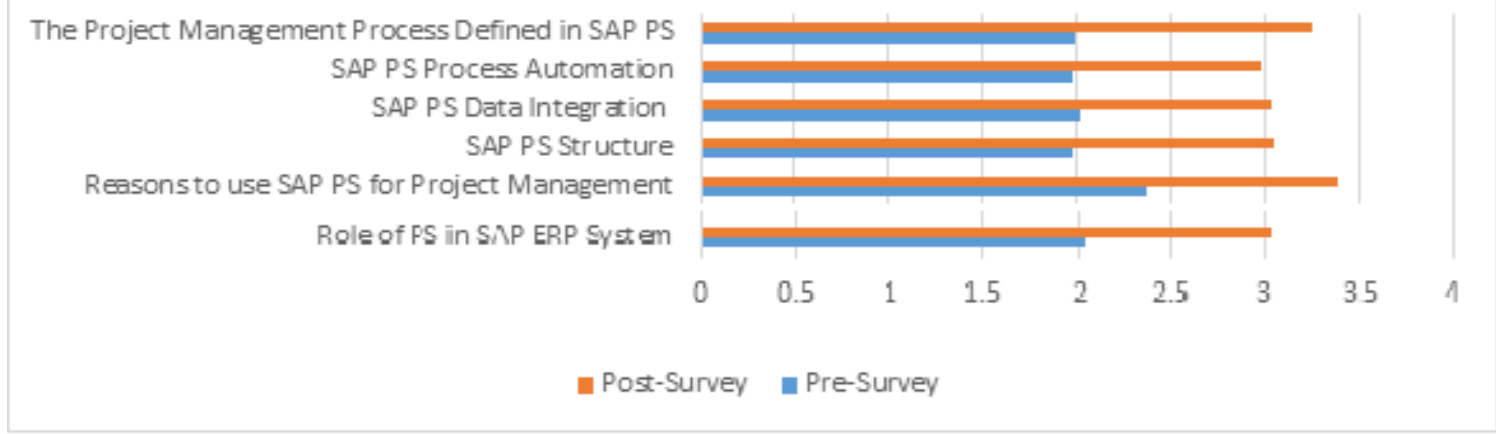

Figure 3. SAP PS Knowledge Pre-Survey and Post-Survey in Spring 2015 and Fall 2015

Figure 4 compares the differences between pre-survey and post survey in terms of SAP PS conceptual knowledge students gained in 2015 spring semester and in 2015 fall semester. As data indicates, overall, students gained more understanding about the conceptual knowledge regarding SAP PS during the fall semester than in the spring semester. This could be because the instructor became more experienced in articulating SAP PS related concepts before providing students with hands on tutorials. More specifically, students seem to gain better comprehension in terms of the reasons why SAP PS is used for project management purposes and the differences between SAP PS and Microsoft Project as project management tools. 


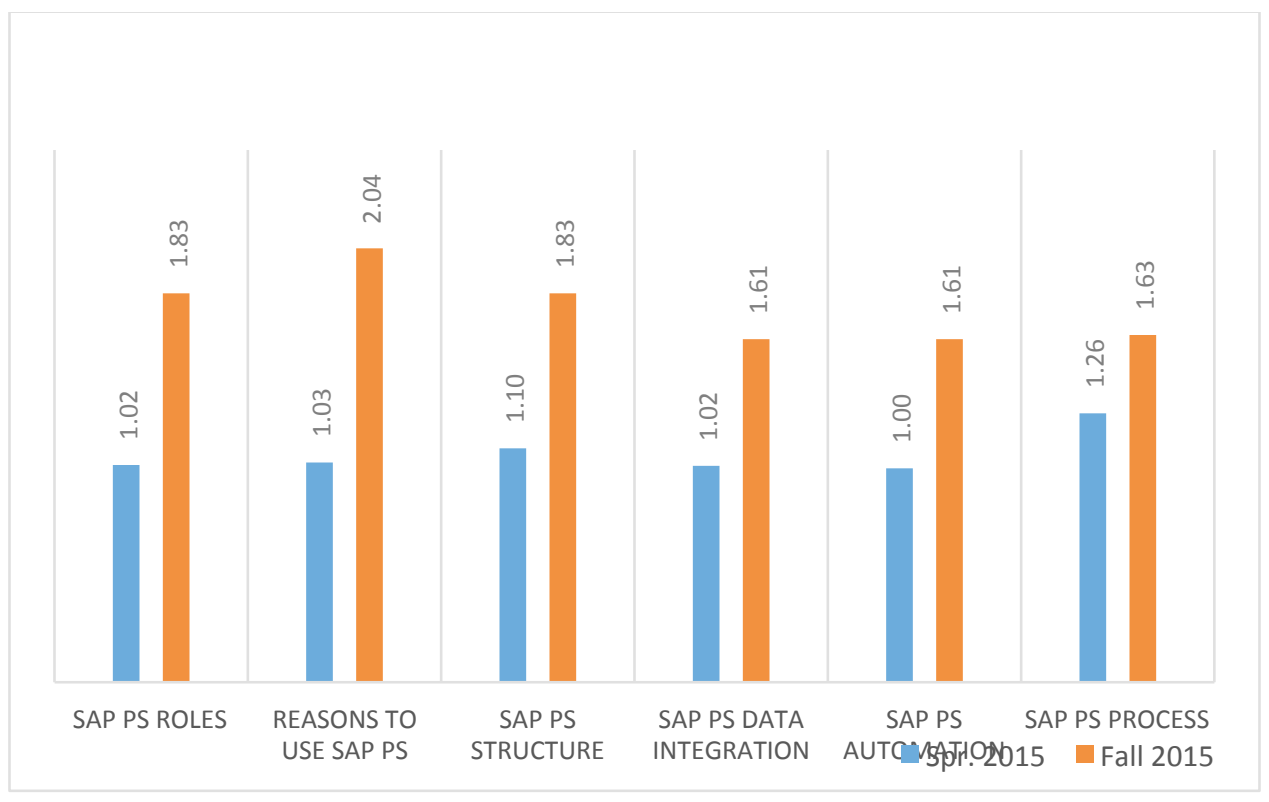

Figure 4. SAP PS Knowledge Gain in Spring 2015 vs. Fall 2015

Figure 5 shows significant improvement in SAP PS related skills after hands-on SAP PS exercises. Project Releasing achieves the highest rating among the other skills. This suggests students understand the importance of the concept of project releasing — which is a milestone activity that ends the project planning stage and starts the project execution stage within the project management lifecycle.

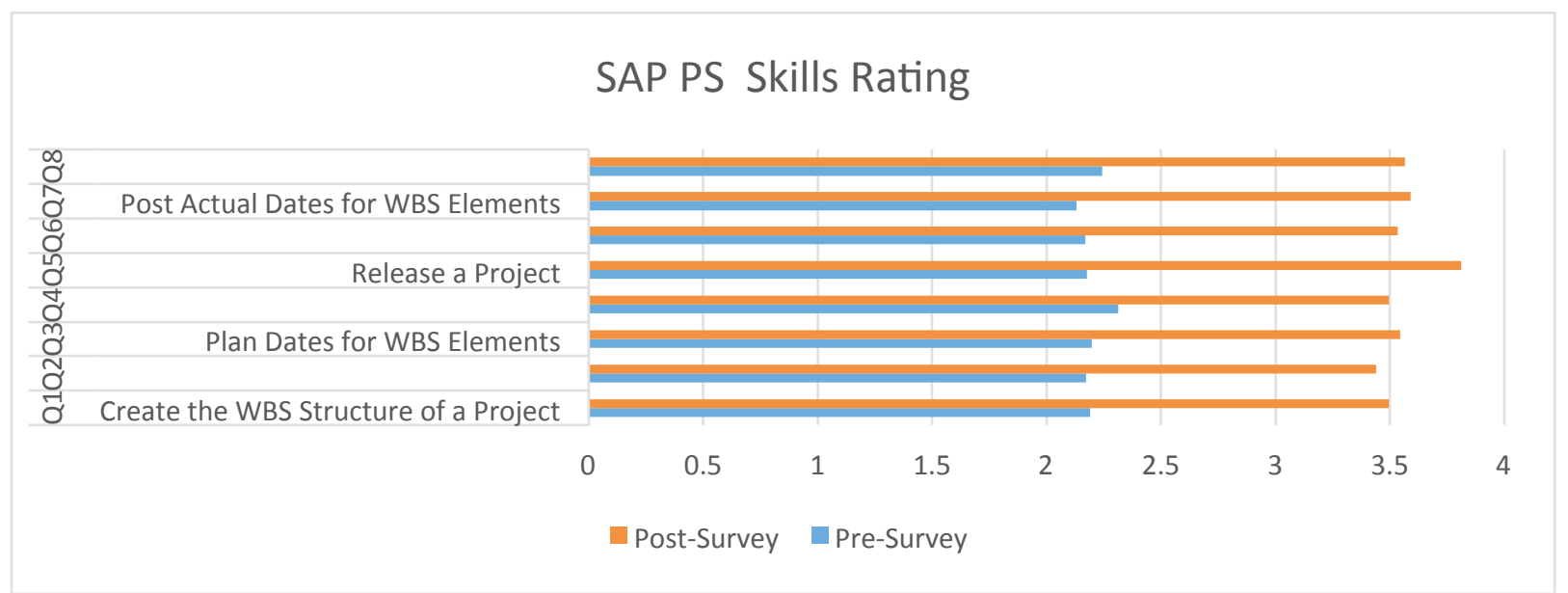

Figure 5. SAP Project PS Skills in Pre-Survey and Post-Survey in in Spring 2015 and Fall 2015

Figure 6 compares the differences between pre-survey and post survey in terms of SAP PS practical skills students who gained in the 2015 spring semester and in the 2015 fall semester. Again, the figure illustrates that students acquired more practical skills on how to use SAP PS during the fall semester than in the spring semester. These additional skill gains could be attributed to the fact that the instructor allocated a little bit more time for students to practice SAP PS hands on tutorial during the fall semester than in the spring semester. Some specific aspects of SAP PS skills that students achieved significant growth (close to 2 points) include: creating reports on project plan, 
creating WBS structure, and planning costs using cost models. These skills potentially enhance students' capability in integration management, scope management, cost management, and communication management.

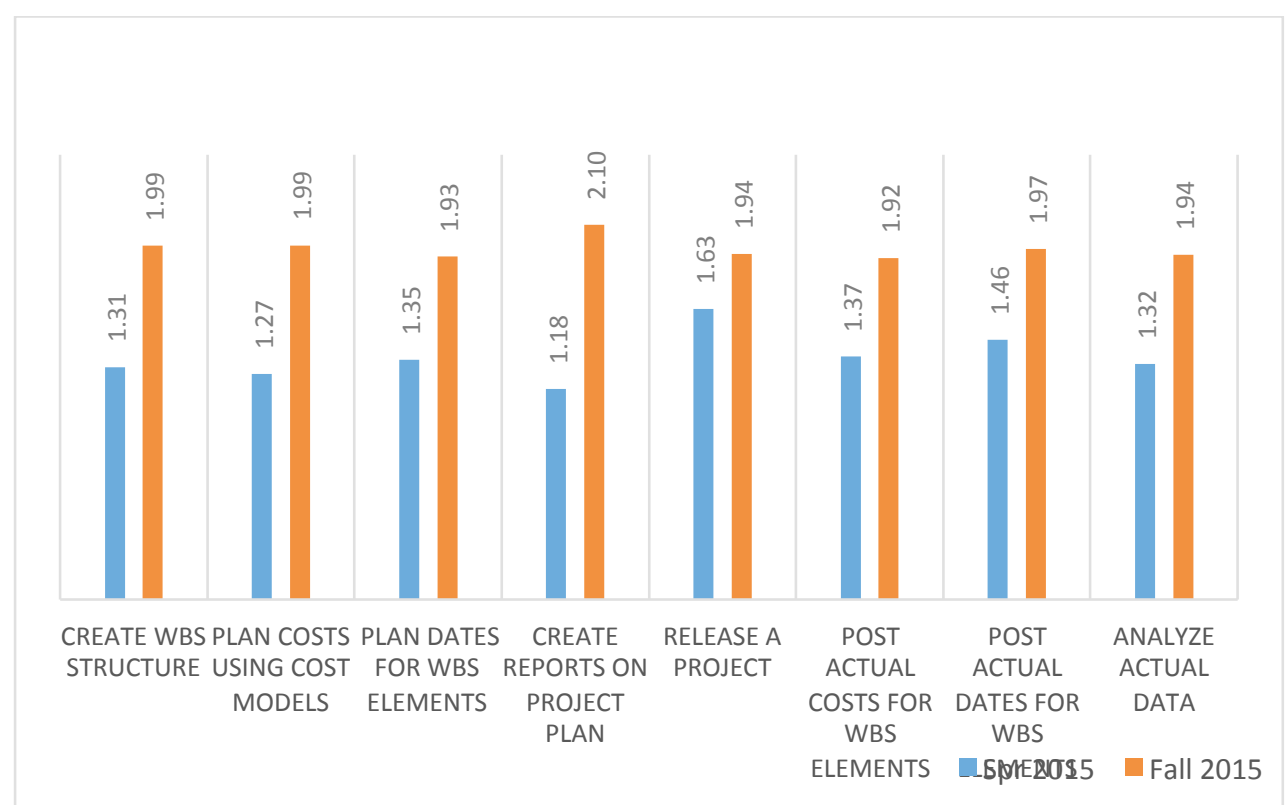

Figure 6. SAP PS Skill Gain in Spring 2015 vs. Fall 2015

Figure 7 shows that students learning experience ratings are very positive in all six areas for both spring and fall semesters. It is evident that introducing the SAP PS as part of the curriculum helps students to achieve positive experience and expectations in learning IS project management. They are also more enthusiastic and interested in learning more about SAP PS. However, confidence in understanding SAP PS received the lowest rating (3.1) in fall 2015 , this is because learning curve of SAP PS is rather steep, especially for students who do not have prior knowledge of SAP ERP system. 


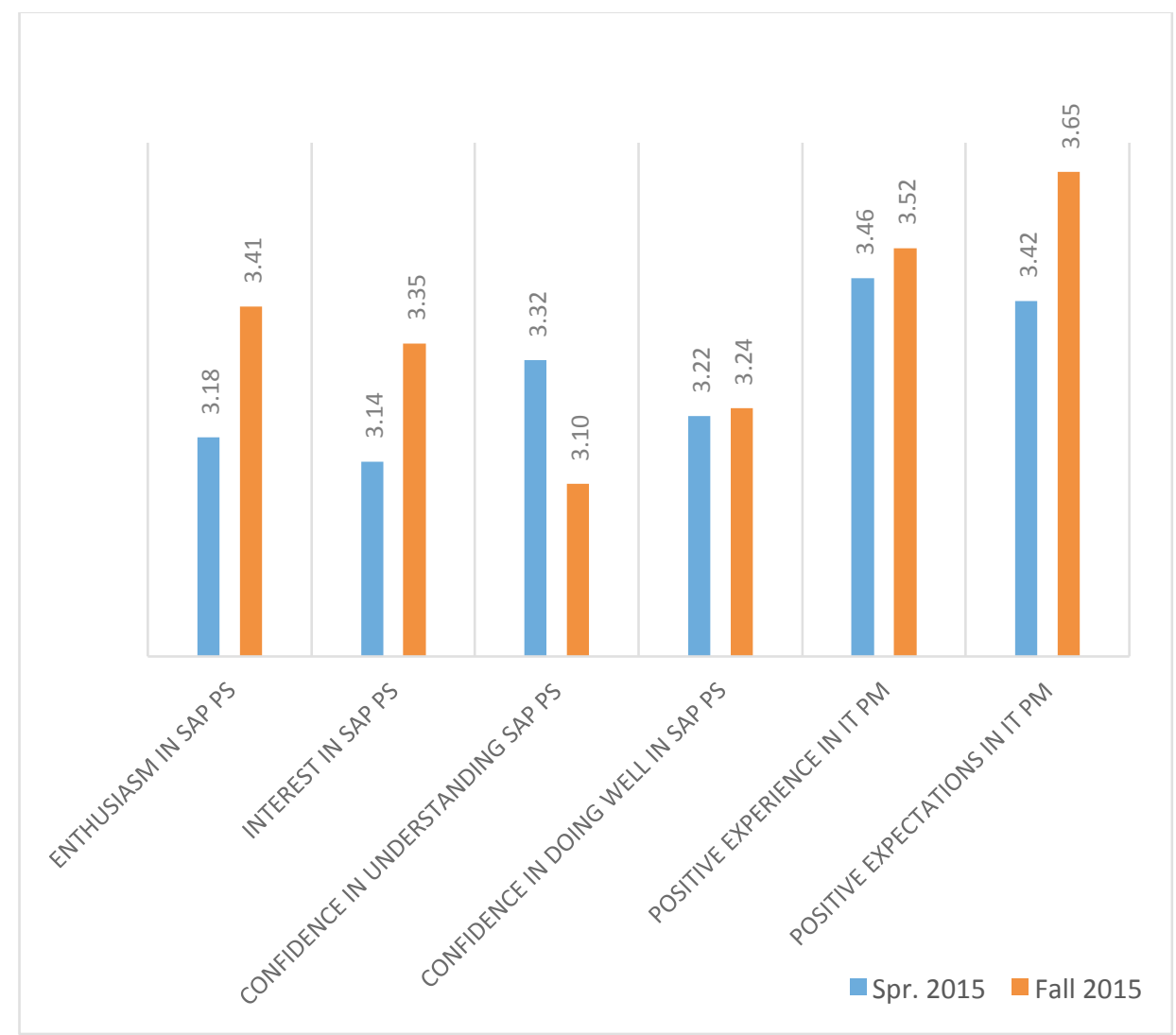

Figure 7. SAP PS Learning Experience Post-Survey in Spring 2015 vs. Fall 2015

\section{CONCLUSION}

The authors proposed a comprehensive framework to introduce an ERP-based project management tool in the project management course, and also assessed student learning outcomes from the course using survey instruments. The contribution of the paper is to provide IS educators an innovative approach to integrate SAP ERP Project System into an IS project management course, as defined in the IS 2010 Curriculum Guidelines ((Topi, et al., 2010). The study introduces course design, course material, and delivery methods. The data analysis of the preliminary surveys indicate successful learning outcomes and positive learning experiences as result of learning SAP ERP Project System in the IS project management course. Some students also received internships and full time positions in SAP ERP client companies after taking the course.

\section{ACKNOWLEDGEMENTS}

Authors are grateful to the SAP University Alliance Program for providing SAP Project System server hosting and electronic curriculum materials.

\section{REFERENCEES}

Anderson, G. W., Nilson, C. D., \& Rhodes, T. (2009). SAP implementation, unleashed: A business and technical roadmap to deploying SAP. Old Tappan, NJ: Pearson Education.

CHAOS, The Standish Group Report (1995). https://www.projectsmart.co.uk/white-papers/chaos-report.pdf 


\section{Issues in Information Systems}

Volume 17, Issue IV, pp. 42-50, 2016

Franz, M., (2015). Project Management with SAP Project System, 4th Edition, SAP Press.

Hackney, R. A., McMaster, T., \& Harris, A. (2007). Using cases as a teaching tool in IS education. Journal of Information Systems Education, 14(3), 229-234.

Huang, D. Ma, Zhongming and Wang, M., (2014). The Information Systems Core: A Study from the Perspective of IS Core Curricula in the U.S., Information Systems Education Journal (ISEDJ), 13(6), 27-34.

Marchewka, J., (2012). Information Technology Project Management. John Wiley \& Sons, Inc.

Project White Paper (2012) Microsoft Project Server 2010 Integration with SAP. go.microsoft.com/fwlink/p/?LinkId=238716

Project Management Institute, Inc., (2008). A Guide to the Project Management Body of Knowledge: PMBOK(R) Guide, 5th Edition.

Rosenthal, P. and Dhariwal, K., (2015). Proposed IS 2015 Model Curriculum reflecting the emerging IS Profession, The Business Forum Journal, http://www.bizforum.org/Journal/www_journalPHR2015.htm

Topi, H., Valachic, J.S., Wright, R.T., K. Kaiser, Nunamaker, J.F. Jr., Sipior, J.C., \& de Vreede, G.J. (2010). IS 2010: Curriculum Guidelines for Undergraduate Degree Programs in Information Systems. Communications of the Association for Information Systems, 26(18), 359-428.

Diaz, A., Wassmann, M. and Wilde, T., (2012). Project Management Using SAP Project Systems, Use with the IDES Data Set, SAP University Alliance Curriculum Series. http://scn.sap.com/docs/DOC-42378 